\title{
Vasa Vasorum Hypoperfusion Is Responsible for Medial Hypoxia and Anatomic Remodeling in the Newborn Lamb Ductus Arteriosus
}

\author{
HIROKI KAJINO, SETH GOLDBARG, CHRISTINE ROMAN, BAO MEI LIU, \\ FRANÇOISE MAURAY, YAO QI CHEN, YASUSHI TAKAHASHI, CAMERON J. KOCH, AND \\ RONALD I. CLYMAN \\ Cardiovascular Research Institute [H.K., S.G., C.R., B.M.L., F.M., Y.Q.C., Y.T., R.I.C.] and Department of \\ Pediatrics [R.I.C.], University of California, San Francisco, San Francisco, CA, 94143, U.S.A.; and \\ Department of Radiation Oncology [C.J.K.], University of Pennsylvania, Philadelphia, PA, 19104, U.S.A.
}

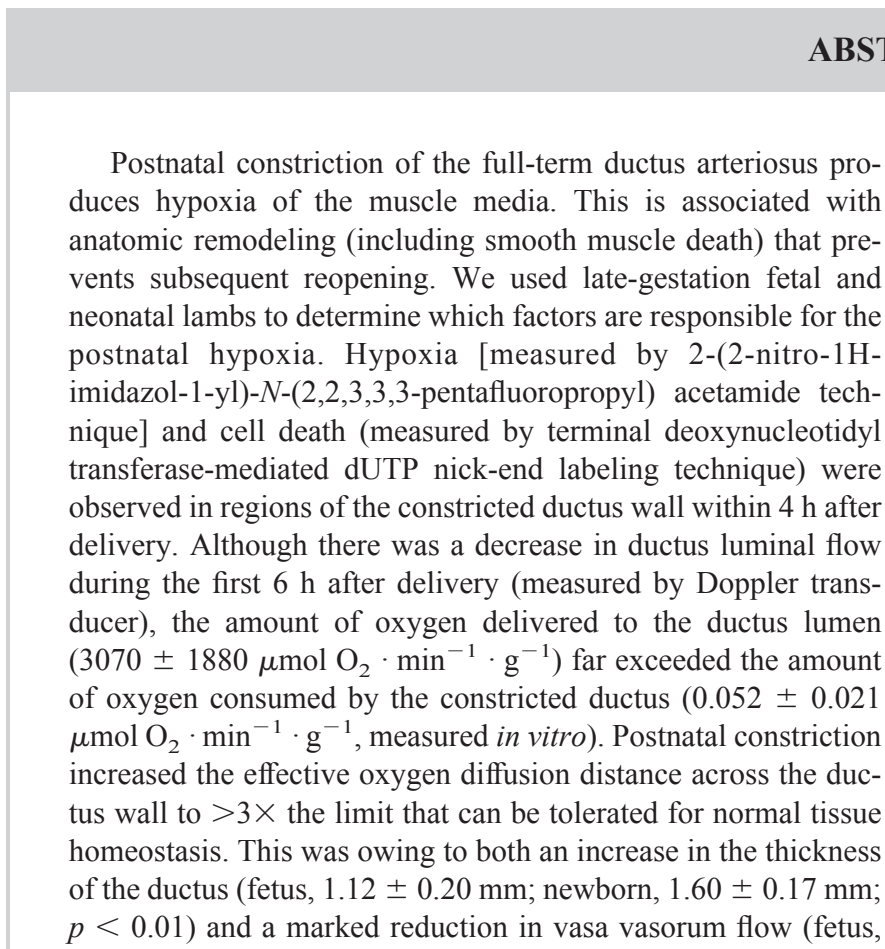

$0.99 \pm 0.44 \mathrm{~mL} \cdot \min ^{-1} \cdot \mathrm{g}^{-1} ;$ newborn, $0.21 \pm 0.08 \mathrm{~mL} \cdot$ $\left.\min ^{-1} \cdot \mathrm{g}^{-1} ; p<0.01\right)$. These findings suggest that hypoxic cell death in the full-term ductus is caused primarily by changes in vasa vasorum flow and muscle media thickness and can occur before luminal flow has been eliminated. We speculate that in contrast with the full-term ductus, the preterm ductus is much less likely to develop the degree of hypoxia needed for vessel remodeling inasmuch as it only is capable of increasing its oxygen diffusion distance to $1.3 \times$ the maximally tolerated limit.

(Pediatr Res 51: 228-235, 2002)

DA, ductus arteriosus

\section{Abbreviations}

eNOS, endothelial nitric oxide synthase

EF5, 2-(2-nitro-1H-imidazol-1-yl)- $N$-(2,2,3,3,3-

pentafluoropropyl) acetamide

TUNEL, terminal deoxynucleotidyl transferase-mediated

dUTP nick-end labeling

$\mathrm{PaO}_{2}$, arterial $\mathrm{PO}_{2}$

$\mathrm{PaCO}_{2}$, arterial $\mathrm{PCO}_{2}$
In the full-term infant, closure of the DA occurs in two phases: first, smooth muscle cell constriction produces a functional closure of the DA lumen; this is followed by permanent, anatomic occlusion of the lumen caused by extensive neointimal thickening and loss of smooth muscle cells from the inner muscle media (1). The initial functional constriction produces a zone of hypoxia in the muscle media of the DA, which

Received July 18, 2001; accepted July 24, 2001.

Correspondence and reprint requests: Ronald I. Clyman, M.D., Box 0544, HSE 1492, University of California, San Francisco, 505 Parnassus Avenue, San Francisco, CA 94143-0544, U.S.A.; e-mail: ric@itsa.ucsf.edu

Supported in part by U.S. Public Health Service National Heart, Lung, Blood Institute grants HL 46691 and HL 56061, and a gift from the Perinatal Associates Research Foundation. S.G. is a research fellow with the Stanley J. Sarnoff Endowment for Cardiovascular Research. appears to be responsible for the ultimate anatomic closure of the DA (1). In contrast with the full-term ductus, the preterm ductus fails to develop the same degree of hypoxia after birth. This failure occurs in spite of developing similar degrees of constriction as the full-term ductus. The absence of hypoxia prevents the preterm DA from remodeling and leads to subsequent DA reopening after its initial constriction $(1,2)$. In the following study we examined the mechanism by which postnatal constriction produces hypoxia in the DA wall.

Oxygen normally reaches the muscle media of the fetal DA through either the vessel lumen or its vasa vasorum. The muscle media of most vessels has a region, adjacent to the lumen, that lacks vasa vasorum (3). This avascular zone depends on diffusion from both the lumen and vasa vasorum to 
meet its oxygen needs and therefore is particularly vulnerable to changes in oxygen supply (4-7). Three separate factors can lead to hypoxia within this region: 1 ) a decrease in luminal or vasa vasorum blood flow, 2) an increase in the diffusion distance (or thickness) of the avascular zone, or 3) an increase in the oxygen consumption of the muscle media $(1,4-9)$.

Vasa vasorum penetrate the muscle media to varying depths depending on the thickness of the vessel wall $(3,10-12)$. Blood vessels thinner than $0.5 \mathrm{~mm}$, like the extremely preterm human DA (Fig. 1), have no vasa vasorum in the muscle media and are nourished by diffusion from the lumen or adventitial vasa vasorum. In contrast, vessels thicker than $0.5 \mathrm{~mm}$, such as the late-gestation human DA (Fig. 1), have a dense network of intramural vasa vasorum in the outer layers of the muscle media in addition to the adventitial vasa vasorum (3). In the following study we hypothesized that the dependence of the full-term DA on intramural vasa vasorum flow (to meet its oxygen needs) might play a role in its increased susceptibility to developing hypoxia during postnatal constriction.

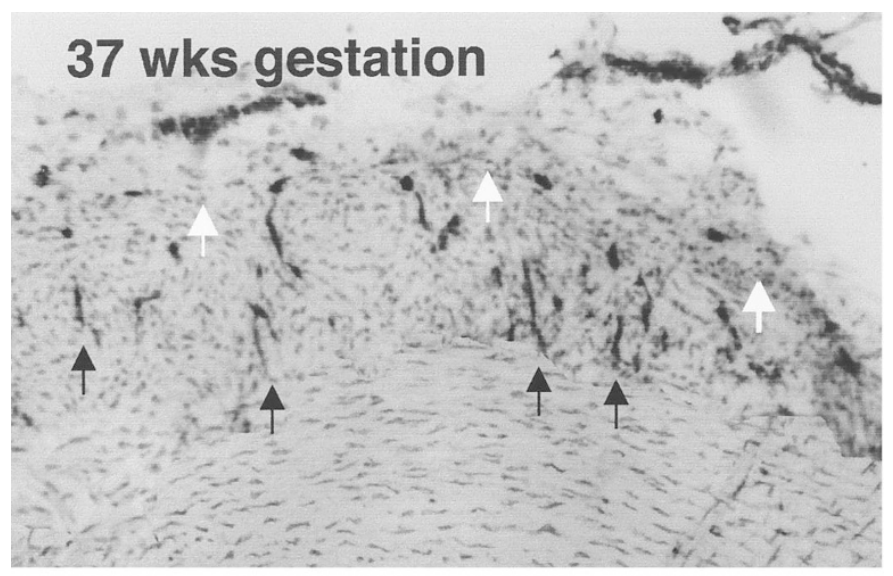

\section{4 wks gestation}

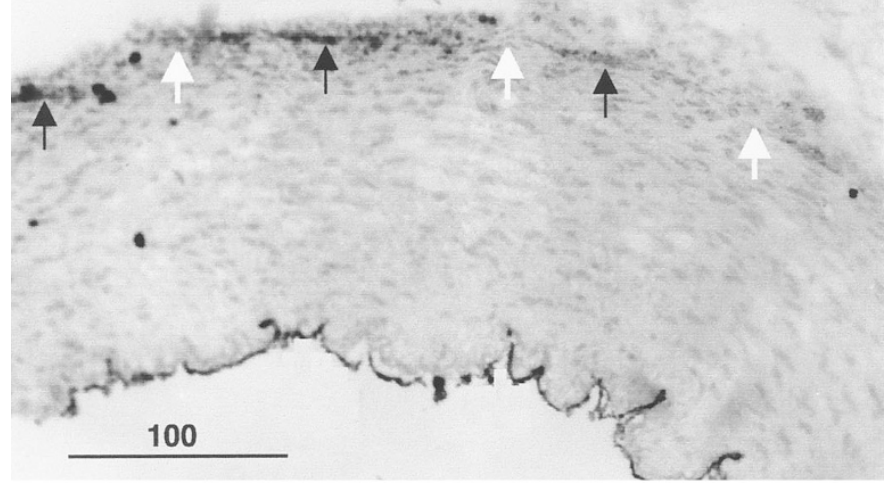

Figure 1. Vasa vasorum are present in the outer muscle media of the late-gestation human ductus ( $37 \mathrm{wk}$ ) but not in the immature (24 wk) ductus. Tissue was obtained from newborn human infants who died within $24 \mathrm{~h}$ of birth. Sections were stained for eNOS to identify endothelial cells in vasa vasorum and counterstained with hematoxylin. Black arrows indicate the leading edge of the vasa vasorum. White arrows indicate the border of the adventitia with the muscle media. Horizontal bar $=100 \mu \mathrm{m}$.

\section{METHODS}

All studies were approved by the Committee on Animal Research at the University of California San Francisco.

Tissue hypoxia, cell death, and ductus wall dimensions. Late-gestation fetal lambs [mixed Western breed, $138 \pm 2 \mathrm{~d}$ gestation (term $=145 \mathrm{~d}$ gestation), $n=7$ ] and spontaneously delivered newborn lambs $(n=8)$ were used to study the appearance of hypoxia and cell death in the DA wall. Fetuses were delivered by cesarean section and killed before breathing. Newborns were killed with an overdose of pentobarbital sodium at 4,14 , and $24 \mathrm{~h}$ after delivery. At necropsy, the DA was dissected in $4^{\circ} \mathrm{C}$ Dulbecco's PBS, embedded in Tissuetek (Sakura Finetek, Inc., Torrance, CA, U.S.A.) and frozen in liquid nitrogen.

Detection of hypoxia with EF5. To detect regions of hypoxia within the DA we used the EF5 detection system that we have described previously $(1,13)$. The rate of EF5 binding increases as $\mathrm{O}_{2}$ concentrations decrease over the range 10 to $0.01 \%(1,14,15)$. Spontaneously delivered, full-term lambs were given EF5 (0.1 $\mathrm{mmol} / \mathrm{kg}$, i.v.) $1 \mathrm{~h}$ after delivery ( $23 \mathrm{~h}$ before necropsy). Fetal lambs were given a 4-h i.v. infusion of EF5 $\left(0.1 \mathrm{mmol} \cdot \mathrm{kg}^{-1}\right.$. $\mathrm{h}^{-1}$ ) starting $24 \mathrm{~h}$ before necropsy (see below for surgical preparation). EF5 binding, at constant $\mathrm{Po}_{2}$, depends on the tissue drug exposure. Therefore, blood samples were collected and analyzed for EF5 as previously described (1).

We used MAb (ELK 3-51), which is highly specific for EF5 and its tissue adducts, to detect the presence of bound EF5 in the tissue $(1,15)$. The MAb (ELK 3-51) was conjugated with the fluorochrome $\mathrm{Cy} 3$, and fluorescence was detected with a calibrated fluorescence imaging system. Image acquisition was performed with a Photometrics Quantix charge-coupled device camera (Tucson, AZ, U.S.A.), and the digitized images were analyzed with National Institutes of Health Image software (Bethesda, MD, U.S.A.) and Adobe Photoshop (Adobe Systems, Mountain View, CA, U.S.A.) (1, 15). EF5 binding was corrected for the in vivo EF5 drug exposure (which was calculated from the area under the curve of EF5 serum concentrations) and was expressed as a percent of the calculated maximal expected binding $(14,15)$. In the newborn lamb the EF5 half-life is $6.5 \mathrm{~h}$; in the fetal lamb it is 75 min owing to loss to the mother across the placenta.

Cell death. We used the TUNEL technique to detect cells in the early stages of DNA fragmentation and cell death as we have described previously (1). The number of TUNEL-positive nuclei per 500 nuclei was measured in a $67-\mu \mathrm{m}$-wide area through the middle of the muscle media in the region of EF5 staining. Regions of the section that had negligible EF5 binding had no TUNEL-positive nuclei (see below).

Vasa vasorum perfusion: i.v. Hoechst bis-benzimide technique. In some of the lambs the DNA-binding dye, Hoechst (No. 33342) bis-benzimide (Sigma Chemical Co., St. Louis, MO, U.S.A.; $20 \mathrm{mg} / \mathrm{kg}$, i.v.), was administered $15 \mathrm{~min}$ before necropsy. This fluorescent dye readily intercalates into cellular DNA and can be used to demonstrate regions of the DA that were perfused and had access to the dye (as measured by Hoechst-bis-benzimide uptake) just before necropsy. 
Immunohistochemistry. We used a mouse MAb against eNOS (Clone 3, Transduction Lab, Lexington, KY, U.S.A.) to identify endothelial cells lining the DA lumen and vasa vasorum as previously reported $(1,16)$. Histologic measurements were made at the level of minimal luminal area, which was determined from serial sections made through the tissue. Tissue dimensions and zone thicknesses were determined by averaging measurements made from eight predetermined regions of the section, using an overlay template and NIH Image software (16). We defined the avascular zone of the DA as the region of the DA wall between the endothelial lining of the DA lumen and the leading edge of the vasa vasorum. The total muscle media thickness was defined as the region between the luminal endothelium and the outer layer of smooth muscle cells in the muscle media.

Ductus luminal and vasa vasorum blood flow. Pregnant sheep ( $n=21,135 \pm 0.6 \mathrm{~d}$ gestation) were operated on under i.v. ketamine hydrochloride and diazepam anesthesia $(16,17)$. The fetus was exposed through a uterine incision, and catheters were inserted into the ascending aorta, superior vena cava, descending aorta, and inferior vena cava through the forelimb and hindlimb pedal artery and vein, respectively. A catheter was inserted into the pulmonary artery directly by means of a thoracotomy. In six fetuses, a 4- to 6-mm Doppler flow transducer (Transonics Systems, Ithaca, NY, U.S.A.) was placed around the DA to measure luminal blood flow. In eight fetuses, catheters were placed in the left and right ventricles through the carotid artery and jugular vein, respectively, for microsphere injections. The thoracotomy was closed, and the fetus was returned to the uterus for subsequent experimentation.

Experimental protocols. Fetuses were studied between 24 and $48 \mathrm{~h}$ after surgery. In the first group $(n=7$, described above), EF5 was infused into the fetus $24 \mathrm{~h}$ before necropsy to determine the incidence of hypoxia and cell death in the fetal DA.

In the second group $(n=6)$, continuous Doppler measurements of DA luminal blood flow were recorded for $1 \mathrm{~h}$ before delivery. After maternal anesthesia, the fetus was exposed through a uterine incision and given ketamine hydrochloride. The fetal trachea was intubated, and Infasurf ( $3 \mathrm{~mL} / \mathrm{kg}$; Ony, Amherst, NY, U.S.A.) was instilled into the airway to preclude the possibility of surfactant deficiency. The fetal lamb was then mechanically ventilated with a time-cycle pressure-limited ventilator while still connected to the placenta (17). The ventilator settings were peak inspiratory pressure, $28 \mathrm{~cm} \mathrm{H}_{2} \mathrm{O}$; positive end-expiratory pressure, $5 \mathrm{~cm} \mathrm{H}_{2} \mathrm{O}$; inspiratory time, $0.4 \mathrm{~s}$; respiratory rate, 50 breaths $/ \mathrm{min}$; and fractional inspired oxygen concentration, 1.0. Peak inspiratory pressures and ventilator rates were reduced to maintain a $\mathrm{PaCO}_{2}$ between 30 and $35 \mathrm{~mm} \mathrm{Hg}$; other ventilator settings remained constant. The beginning of mechanical ventilation was considered the time of delivery $(0 \mathrm{~h})$. The umbilical cord was clamped, after $30 \mathrm{~min}$ of ventilation, and the lamb was delivered into a $37-38^{\circ} \mathrm{C}$ water bath. The initial 30-min period of ventilation, with the lamb still attached to the placenta, was used to ensure adequate lung expansion without the need for high initial inspiratory pressures. We chose to ventilate lambs with $100 \%$ oxygen as hyperoxemic animals $\left(\mathrm{PaO}_{2}>250 \mathrm{~mm} \mathrm{Hg}\right)$ have a tighter degree of DA constriction and develop a more profound degree of DA wall hypoxia after birth than normoxemic animals ( $\left.\mathrm{PaO}_{2}, 80-100 \mathrm{~mm} \mathrm{Hg}\right)$ (14).

Pulmonary and systemic arterial pressures and DA luminal blood flows were monitored continuously throughout the 6-h neonatal study period. Arterial $\mathrm{pH}, \mathrm{PaCO}_{2}$, and $\mathrm{PaO}_{2}$ were measured on a Radiometer Blood Gas Analyzer (Radiometer, Copenhagen, Denmark); oxygen saturation and $\mathrm{Hb}$ concentration were measured on an OSM-2 Hemoximeter (Radiometer). Arterial oxygen content was calculated as the following product: $[(\mathrm{Hb}$ concentration $) \times(\%$ oxygen saturation $) \times(1.34 \mathrm{~mL}$ $\left.\left.\mathrm{O}_{2} / \mathrm{g} \mathrm{Hb}\right)\right]$. We disregarded the contribution of the dissolved oxygen in our calculations of oxygen delivery. At $6 \mathrm{~h}$, the lambs were given a lethal dose of pentobarbital sodium and a necropsy was performed.

In the third group $(n=8)$, fluorescent microspheres (Interactive Medical Technologies Ltd., Irvine, CA, U.S.A.) were used to determine vasa vasorum blood flow by methods similar to those published previously (18). Fetuses were prepared surgically as described above (except no Doppler flow probe was present). Microsphere measurements were made both before and during the $6 \mathrm{~h}$ of mechanical ventilation (at 2 and $4.5 \mathrm{~h}$ ). For each microsphere measurement, two separate sets of fluorescent microspheres (approximately $3 \times 10^{6}$; size, $15 \mu \mathrm{m}$ ) were injected simultaneously into the right and left ventricles. Reference blood samples were withdrawn from the ascending and descending aorta. We previously found that blood flow to the vasa vasorum of the DA is derived from the ascending and descending aorta but not from the pulmonary artery (data not shown). After the experiment the DA, ascending aorta, and reference blood samples were weighed and digested in alkali, and the released fluorescent microspheres were counted by flow cytometry (19). Process control microspheres were added to each tissue or blood sample to determine the number of microspheres lost during sample processing (recovery, $86 \pm$ $10 \%)$. Vasa vasorum blood flow was calculated from the number of microspheres in the vessel, divided by the number of microspheres in the appropriate reference arterial blood sample(s), and multiplied by the reference blood flow(s).

Oxygen consumption in vitro. Fetal lambs $(134 \pm 2 \mathrm{~d}$ gestation, $n=11$ ) were anesthetized with ketamine hydrochloride before rapid exsanguination. The ductus was divided into two rings ( $36 \pm 9 \mathrm{mg}$ wet weight), which were mounted at an optimal length for tension development $(6.0 \pm 0.7 \mathrm{~mm}$; passive starting tension, $\left.1.16 \pm 0.25 \mathrm{~g} / \mathrm{mm}^{2}\right)(20)$ in a $37^{\circ} \mathrm{C}$, waterjacketed glass chamber equipped with an $\mathrm{O}_{2}$ electrode [see Hellstrand (21)]. A conically ground, 4-cm-tall plastic plug sealed the chamber and contained a small channel through which a freely moveable stainless-steel hook connected the ductus ring to an isometric force transducer. The ductus ring was stretched between the moveable hook and a fixed hook within the chamber. The long diffusion path through the smallbore hole effectively prevented the leakage of $\mathrm{O}_{2}$ into or out of the chamber $(21,22)$. Sterile buffer solution (in $\mathrm{mM}: \mathrm{NaCl}$, 120; $\mathrm{KCl}, 4$; glucose, $10 ; \mathrm{MgCl}_{2}, 1.2 ; \mathrm{KH}_{2} \mathrm{PO}_{4}, 1 ; \mathrm{CaCl}_{2}, 2.6$; HEPES, 25; $\mathrm{pH} 7.45$ ) that had been gassed with $21 \% \mathrm{O}_{2}$ passed through a $0.22-\mu \mathrm{m}$ filter before perfusing the chamber $(1.2 \mathrm{~mL}$ vol) at $0.5 \mathrm{~mL} / \mathrm{min}$. A Teflon-coated magnetic stirrer ensured 
adequate mixing. This apparatus allowed the simultaneous determination of $\mathrm{O}_{2}$ consumption rate and active isometric tension.

The oxygen electrode (YSI model 53 Biologic Oxygen Monitor, Yellow Springs, OH, U.S.A.) was calibrated with $21 \% \mathrm{O}_{2}$-saturated buffer. The solubility of $\mathrm{O}_{2}$ in buffer solution that was equilibrated with $21 \% \mathrm{O}_{2}$ at $37^{\circ} \mathrm{C}$ was assumed to be $0.20 \mu \mathrm{mol} / \mathrm{mL}$ (21). Oxygen consumption rate was measured during a 10-min interval during which the tissue chamber was closed. Background oxygen consumption rate (without tissue) was determined in each experiment and was $11 \%$ of the measured tissue oxygen consumption rate.

The DA rings were initially incubated for $4 \mathrm{~h}$ at $37^{\circ} \mathrm{C}$. During this interval the oxygen consumption rates and isometric tensions stabilized. At $4 \mathrm{~h}, \mathrm{KCl}(90 \mathrm{mM}$, substituted for $\mathrm{NaCl})$, indomethacin $(5.6 \mu \mathrm{M})$, and $N^{\mathrm{G}}$-nitro-L-argininemethyl-ester $(0.1 \mathrm{mM})$ were added to the buffer solution, and changes in isometric tension and oxygen consumption rate were monitored during the next hour. The difference in tensions between the measured tension and the passive tension produced by stretching the ring at the start of the experiment was considered to be the active tension. Tissues were blotted dry and weighed after the experiments. The tension developed in the rings was expressed as the force per unit cross-sectional area $\left(\mathrm{g} / \mathrm{mm}^{2}\right)(20)$.

Statistics. Comparison of unpaired data was performed by the appropriate $t$ test or regression analysis. When more than one comparison was made, Bonferroni's correction was used. Nonparametric data were compared with a Mann-Whitney $U$ test. Results are presented as means $\pm \mathrm{SD}$.

\section{RESULTS}

Spontaneously delivered newborn lambs developed an extensive zone of EF5 binding range, 60 to $100 \%$ of maximal binding [equivalent to oxygen concentrations $<0.2 \%$ (13, 14)]\} and cell death (TUNEL-positive nuclei) in the middle of the DA muscle media (Fig. 2). A significant increase in the number of TUNEL-positive cells was observed as early as $4 \mathrm{~h}$ after delivery (Fig. 2). In contrast, DA from the fetal lambs had negligible EF5 binding (data not shown) and negligible TUNEL-positive nuclei (Fig. 2). The presence of cell death depended on the degree of luminal constriction and EF5 binding. TUNEL-positive cells were found exclusively in regions of the constricted DA wall that had intense EF5 binding (Fig. 2 ). On the other hand, sections of the newborn DA that contained a widely patent lumen (e.g. sections taken near the junction with the descending aorta and distal from the central constricted region) had no detectable EF5 binding and negligible TUNEL-positive nuclei (data not shown). Therefore, we examined the individual factors that control DA wall oxygenation to determine how luminal constriction produced DA wall hypoxia.

The isolated lamb DA had a low basal rate of oxygen consumption (Fig. 3). Maximal stimulation of DA constriction produced only a small $(14 \pm 15 \%)$ increase in steady-state oxygen consumption (Fig. 3).

\section{EF5}
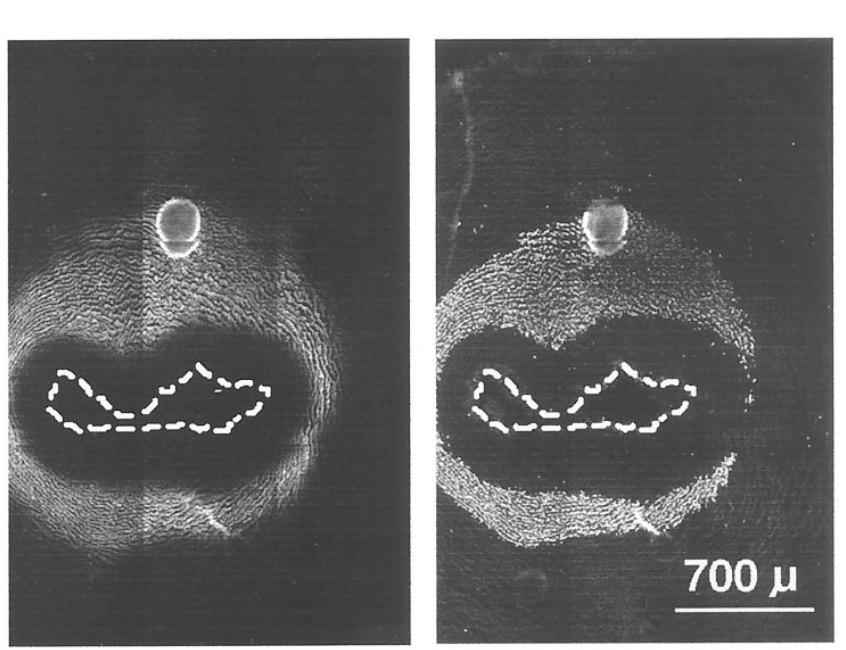

TUNEL
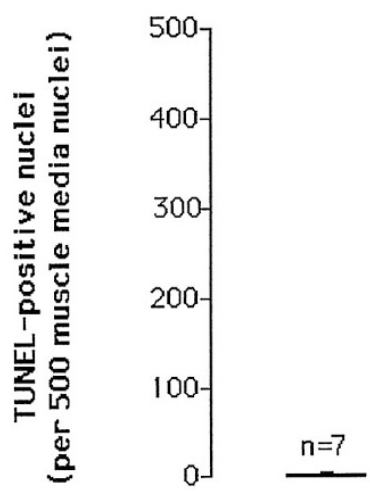

FETUS

Figure 2. Hypoxia (EF5 binding) and cell death (TUNEL staining) in the DA. Upper, ductus was removed from a 24-h-old newborn lamb that had been previously injected with EF5 (see "Methods"). Adjacent 10- $\mu$ m sections from the middle of the ductus were stained with MAb (ELK 3-51) to detect EF5 or with the TUNEL technique to identify DNA fragmentation. There was marked EF5 binding in the middle of the muscle media. Only cells in the region of intense EF5 binding had TUNEL-positive nuclei. Dashed white line represents the ductus lumen (identified by phase-contrast microscopy). Horizontal bar = $700 \mu \mathrm{m}$. Lower, DAs were obtained from late-gestation fetal lambs and from spontaneously delivered newborn lambs at 4,14 , and $24 \mathrm{~h}$ after delivery and examined for DNA fragmentation in the middle of the muscle media. Values are mean $\pm \mathrm{SD}$.

Shortly after delivery, there was a marked reduction in luminal blood flow; however, luminal flow did not drop to zero (Table 1). By $6 \mathrm{~h}$ after birth, oxygen delivery through the DA lumen was still $22 \%$ of fetal values (Table 1). Despite the reduction in luminal flow, the amount of luminal oxygen delivery far exceeded the amount of oxygen consumed by the DA (compare Table 1 with Fig. 3). Therefore, DA hypoxia does not appear to be caused by insufficient luminal oxygen delivery. 

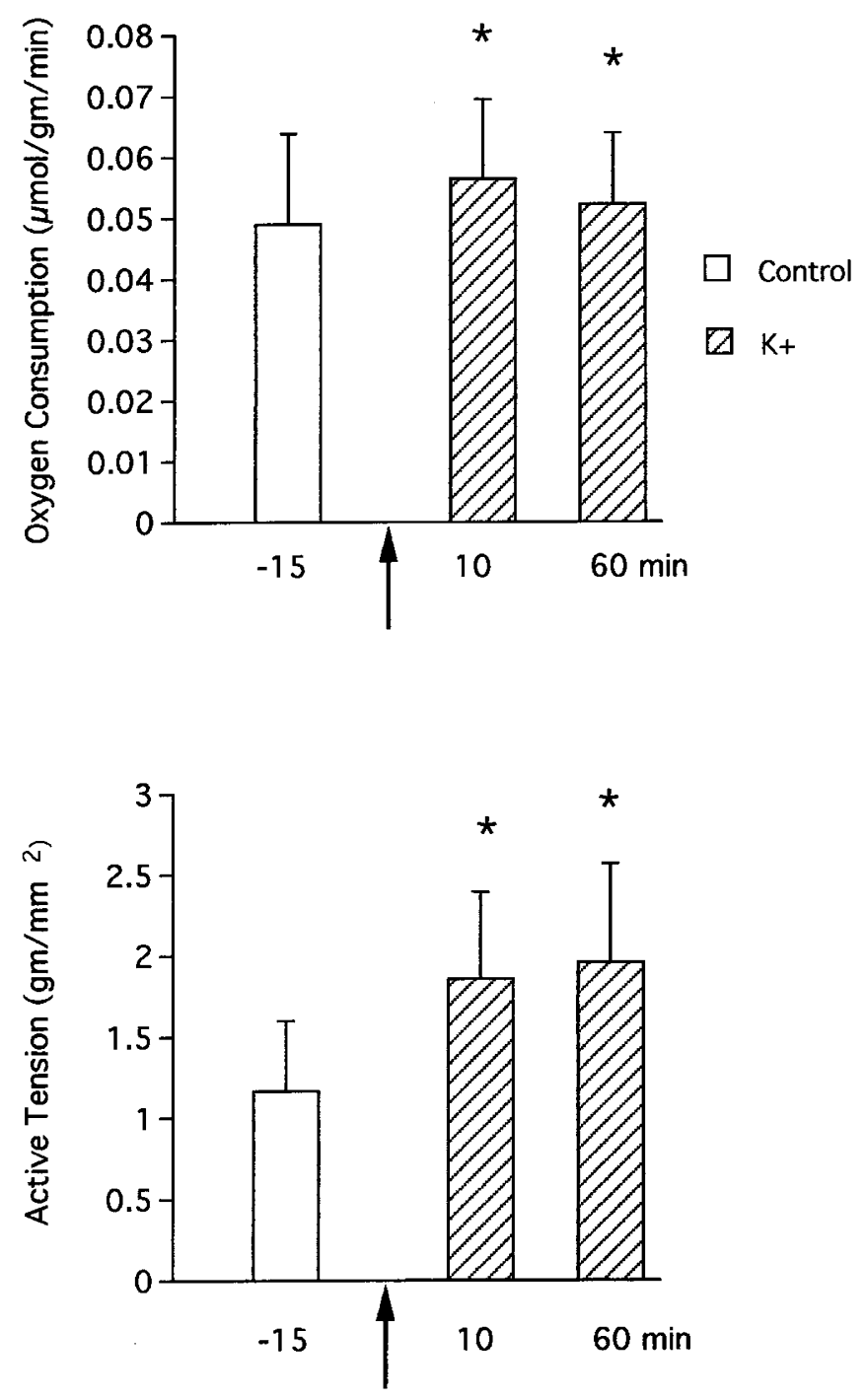

Figure 3. Increasing active tension in ductus rings in vitro has little effect on oxygen consumption $(n=11)$. Ductus rings were incubated in control buffer solution for $4 \mathrm{~h}$ (Control) before exposure to contracting buffer $\left(\mathrm{K}^{+}\right.$) (see "Methods"). Arrows indicate time of solution change. Ten-minute oxygen consumption measurements were made during the control period ( -15 to -5 min before solution change), during the active phase of tension development ( 0 to $10 \mathrm{~min}$ ), and at steady-state tension (50 to $60 \mathrm{~min}$ after solution change). Values are mean $\pm \mathrm{SD} .{ }^{*} p<0.05 v s$ control period.

We examined the effects of DA constriction on oxygen diffusion distance within the DA wall, by measuring the thick-

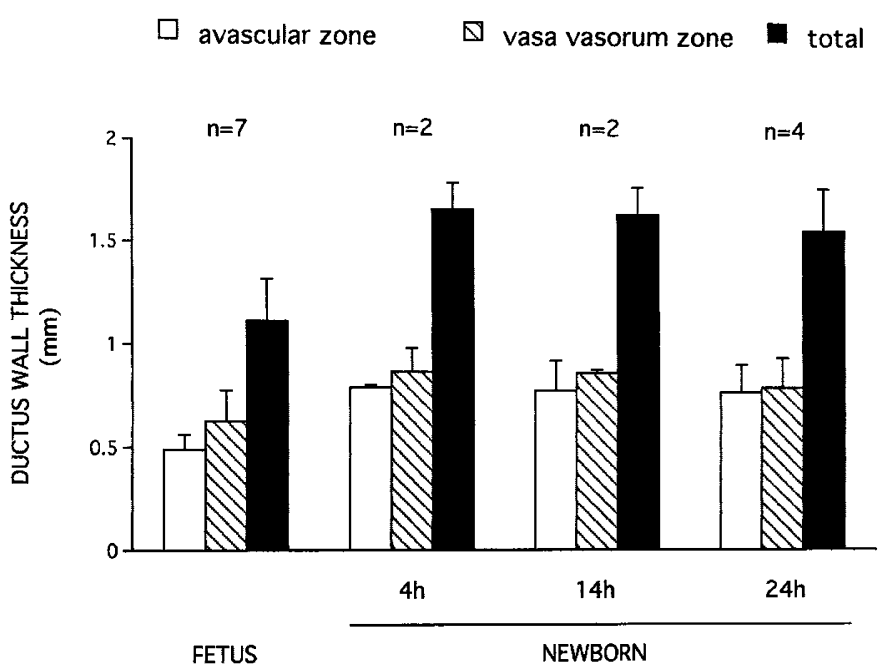

Figure 4. Total wall thickness and avascular zone thickness increase during the first hours after birth (see "Methods" for definitions). DAs were obtained from late-gestation fetal lambs and from spontaneously delivered newborn lambs (see Fig. 2). The smallest areas of the ductus lumen at each time point were fetus, $3.0 \pm 1.6 \mathrm{~mm}^{2}$; newborn $(4 \mathrm{~h}), 0.4 \pm 0.2 \mathrm{~mm}^{2}$; newborn $(14 \mathrm{~h})$, $0.6 \pm 0.5 \mathrm{~mm}^{2}$; newborn $(24 \mathrm{~h}), 0.4 \pm 0.4 \mathrm{~mm}^{2}$. Values are mean $\pm \mathrm{SD}$.

ness of the DA wall, and the distribution of vasa vasorum flow within the DA wall, before and after birth. Shortly after birth there was a significant increase in the thickness of the avascular zone (fetus, $0.489 \pm 0.072 \mathrm{~mm}, n=7$; newborn, $0.775 \pm$ $0.108 \mathrm{~mm}, n=8 ; p<0.01)$ and an increase in the thickness of the total muscle media (fetus, $1.115 \pm 0.200 \mathrm{~mm}, n=7$; newborn, $1.598 \pm 0.168 \mathrm{~mm}, n=8 ; p<0.01$; Fig. 4).

In addition to the increase in DA wall thickness, vasa vasorum flow to the DA wall declined markedly after DA constriction (Fig. 5). To determine whether the decrease in DA vasa vasorum flow was caused by the acute postnatal increase in $\mathrm{PaO}_{2}$, we lowered the fraction of inspired oxygen and measured the vasa vasorum flow $5 \mathrm{~min}$ after $\mathrm{PaO}_{2}$ had achieved a new steady state (Table 2). The decrease in $\mathrm{PaO}_{2}$ did not alter the vasa vasorum flow of either the DA or the aorta (Table 2). Similarly, adenosine, which dilates constricted vasa vasorum (8), had no effect on the diminished vasa vasorum flow after DA constriction (data not shown).

The decrease in vasa vasorum flow was accompanied by a significant change in flow distribution within the DA wall. We injected Hoechst-bis-benzimide into fetal $(n=2)$ and 4-h-old

Table 1. Changes in DA lumen blood flow after birth

\begin{tabular}{|c|c|c|c|c|}
\hline \multirow[b]{2}{*}{ Variable } & \multicolumn{4}{|c|}{ Time after delivery $(\mathrm{h})$} \\
\hline & 0 & 2 & 4 & 6 \\
\hline Ductus lumen blood flow (mL/min) & $(-) 788 \pm 213$ & $272 \pm 204 *$ & $120 \pm 79^{*}$ & $89 \pm 59 *$ \\
\hline Pressure gradient across ductus (mm $\mathrm{Hg}$ ) & $(-) 0.6 \pm 7$ & $21.5 \pm 5.3^{*}$ & $28.0 \pm 5.9^{*}$ & $28.0 \pm 6.4^{*}$ \\
\hline $\mathrm{pH}$ & $7.36 \pm 0.08$ & $7.46 \pm 0.12$ & $7.46 \pm 0.07 *$ & $7.49 \pm 0.06^{*}$ \\
\hline $\mathrm{PaCO}_{2}(\mathrm{~mm} \mathrm{Hg})$ & $50 \pm 3$ & $34 \pm 8^{*}$ & $31 \pm 8^{*}$ & $28 \pm 2 *$ \\
\hline $\mathrm{PaO}_{2}(\mathrm{~mm} \mathrm{Hg})$ & $18 \pm 4$ & $394 \pm 125^{*}$ & $386 \pm 116^{*}$ & $403 \pm 116^{*}$ \\
\hline
\end{tabular}

Values are mean $\pm \mathrm{SD}(n=6) .0 \mathrm{~h}$, fetus immediately before delivery; ductus luminal blood, left-to-right shunt; $(-)$, right-to-left shunt; pressure gradient across ductus, mean systemic arterial pressure - mean pulmonary artery pressure; oxygen delivery to ductus, through ductus lumen. Weight of lambs, $4.00 \pm$ $0.72 \mathrm{~kg}$.

$* p<0.05$ vs $0 \mathrm{~h}$. 


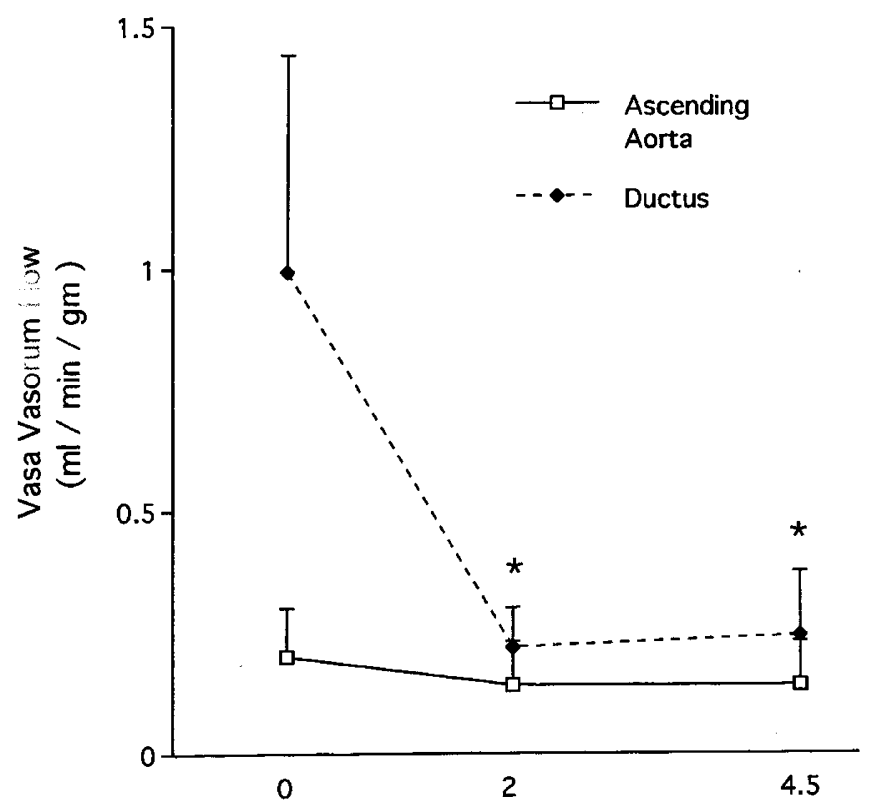

Time After Delivery (hr)

Figure 5. Ductus vasa vasorum blood flow decreases after birth. Microsphere measurements of ductus and ascending aorta vasa vasorum flow were made before $(0 \mathrm{~h})$ and 2 and $4.5 \mathrm{~h}$ after delivery $(n=8)$. Note that vasa vasorum flow to the fetal ductus was $5 \times$ the flow to the fetal aorta $(p<0.01)$. The changes in systemic arterial pressure, pressure gradient across the ductus, $\mathrm{pH}, \mathrm{PaCO}_{2}$, and $\mathrm{PaO}_{2}$ after birth were similar to those reported in Table 1. Values are mean $\pm \mathrm{SD},{ }^{*} p<0.01$ newborn ductus vasa vasorum flow $v s$ fetal values $(0 \mathrm{~h})$.

neonatal $(n=3)$ lambs 15 min before euthanasia to visualize areas of the DA wall that were perfused (Fig. 6). In the fetus, Hoechst-bis-benzimide stained nuclei throughout the entire thickness of the DA wall (Fig. 6A). In contrast, none of the nuclei in the outer half of the 4-h-old newborn DA muscle media were stained by Hoechst-bis-benzimide. Only two narrow regions of the newborn DA were stained: 1 ) the inner media, within $230-280 \mu \mathrm{m}$ of the lumen (Fig. $6 B$ ), and 2) the loose adventitia, outside of the muscle media (Fig. $6 B$ ). There was essentially no vasa vasorum perfusion of the outer muscle media in the constricted newborn DA (Fig. 6, B3). Therefore, as a result of the postnatal ductus constriction, the shortest diffusion distance between the luminal blood flow and the effective vasa vasorum blood flow in the newborn DA was equivalent to the thickness of the total muscle wall $(1.60 \pm$ $0.17 \mathrm{~mm}$, see Fig. 4).

\section{DISCUSSION}

During the first hours after delivery, cells in the center of the late-gestation newborn DA begin to die (Fig. 2). The pattern and location of cell death in the DA wall suggest that profound muscle media hypoxia is responsible for this occurrence (Fig. 2) (1).

DA wall hypoxia cannot be explained by the marked reduction in DA luminal blood flow during the first hours after delivery. The small, persistent left-to-right luminal flow provides more than enough oxygen to meet the needs of DA wall oxygen consumption (Fig. 3, Table 1). Rather, DA wall hyp- oxia appears to be related to a marked increase in the diffusion distance for oxygen across the DA wall (5-7).

Oxygen diffusion distance is usually tightly regulated. The maximal thickness of the avascular zone is determined by the maximal distance that the two sources of oxygen (lumen and vasa vasorum) can be separated while still maintaining normal tissue homeostasis $(3,5-7)$. Although total arterial wall thickness can vary markedly among species, the maximal thickness of the avascular zone, in those arteries that have been studied, remains constant at $<0.5 \mathrm{~mm}(3,10-12)$.

In the late-gestation newborn, there is a marked increase in the distance between the lumen and effective vasa vasorum perfusion during postnatal DA constriction. This is caused by both an increase in the thickness of the avascular zone [owing to tissue compaction $(1,23)$ ] and a reduction in vasa vasorum perfusion of the muscle media (Figs. 5 and 6). The reduction in vasa vasorum flow does not appear to be related to local effects of $\mathrm{PaO}_{2}$ on vasa vasorum tone (Table 2), nor does it appear to be related to a circulating vasoconstrictor as aortic vasa vasorum flow does not change during the same period (Fig. 5). We hypothesize that loss of vasa vasorum flow to the DA muscle media may be related to compression and collapse of the small intramural vasa vasorum during postnatal DA constriction.

The late-gestation fetal DA requires the presence of intramural vasa vasorum to provide nutrients to its outer muscle media. These intramural vasa vasorum provide the DA with a unique mechanism for controlling the maximal diffusion distance across its wall (Fig. 7). By eliminating vasa vasorum flow to the outer muscle media, the newborn DA can turn the entire thickness of its muscle media into a virtual avascular zone (Fig. $7 B$ ). This makes the diffusion distance between the lumen and the effective vasa vasorum flow (in the adventitia) approximately $1.6 \mathrm{~mm}$ (Fig. $7 B$ ). This distance is $>3 \times$ the maximally tolerated diffusion distance of $0.50 \mathrm{~mm}(3,7)$. As a result, profound hypoxia develops even before luminal blood flow is eliminated (7).

In contrast, the extremely preterm DA has no intramural vasa vasorum $(1,24)$ as its wall thickness is $<0.50 \mathrm{~mm}$ (Figs. 1 and $7 C)(3,10-12)$. We have shown previously that when the preterm DA reduces its luminal flow to the same degree as that found at term, the DA wall thickness increases to only $0.67 \mathrm{~mm}$ (1). This diffusion distance is insufficient to produce the profound degree of hypoxia needed for vessel remodeling (Fig. 7D) (1).

These findings help to explain why the preterm DA normally fails to undergo anatomic remodeling after birth. They also suggest a mechanism by which the preterm DA can be made to develop the same degree of profound hypoxia as found at term. Normally, the avascular zone of a vessel depends on oxygen diffusion from both the lumen and vasa vasorum $(7,9,11,25)$. As the maximally tolerated thickness of the avascular zone appears to be $\leq 0.5 \mathrm{~mm}$, the maximally tolerated vectorial oxygen diffusion distance, from either the lumen or vasa vasorum, to the center of the avascular zone must be $\leq 0.25$ $\mathrm{mm}$; this assumes that both sources of oxygen contribute equally to oxygen balance in the DA wall (Fig. 7, $A$ and $C$ ). We hypothesize that the preterm DA can develop the same degree of hypoxia as found at term if it can be made to obliterate its 
Table 2. $\mathrm{PaO}_{2}$ does not alter vasa vasorum flow

\begin{tabular}{lcc}
\hline \multicolumn{1}{c}{ Variable } & Hyperoxia & Hypoxia \\
\hline $\mathrm{PaO}_{2}(\mathrm{~mm} \mathrm{Hg})$ & $249 \pm 91$ & $33 \pm 7$ \\
$\mathrm{PaCO}_{2}(\mathrm{~mm} \mathrm{Hg})$ & $36 \pm 5$ & $33 \pm 7$ \\
$\mathrm{pH}$ & $7.33 \pm 0.04$ & $7.37 \pm 0.04$ \\
Systemic arterial pressure $(\mathrm{mm} \mathrm{Hg})$ & $56 \pm 7$ & $59 \pm 6$ \\
Pressure gradient across ductus $(\mathrm{mm} \mathrm{Hg})$ & $26 \pm 11$ & $23 \pm 11$ \\
Ductus vasa vasorum flow $\left(\mathrm{mL} \cdot \mathrm{min}^{-1} \cdot \mathrm{gm}^{-1}\right)$ & $0.28 \pm 0.14$ & $0.27 \pm 0.11$ \\
Ascending aorta vasa vasorum flow $\left(\mathrm{mL} \cdot \mathrm{min}^{-1} \cdot \mathrm{gm}^{-1}\right)$ & $0.16 \pm 0.09$ & $0.18 \pm 0.18$ \\
\hline
\end{tabular}

Values are mean $\pm \mathrm{SD}(n=5)$. Measurements were made $5 \mathrm{~h}$ after delivery. Pressure gradient across ductus, mean systemic arterial pressure - mean pulmonary arterial pressure.

Fetus
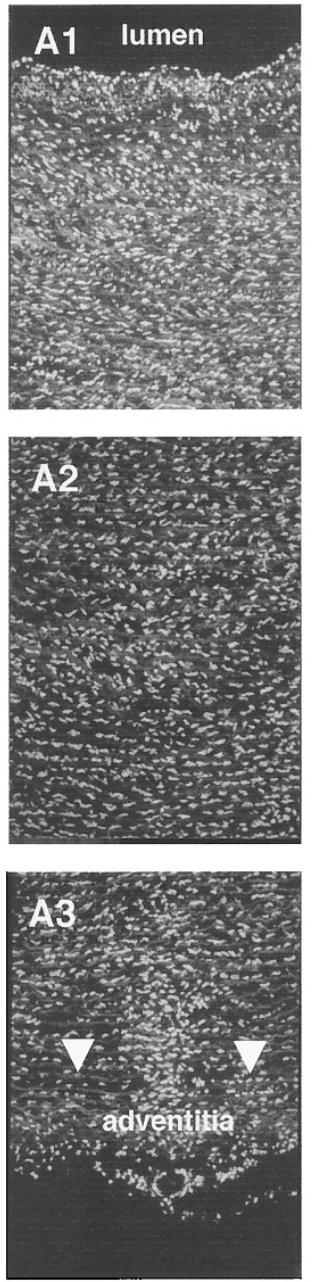

Newborn
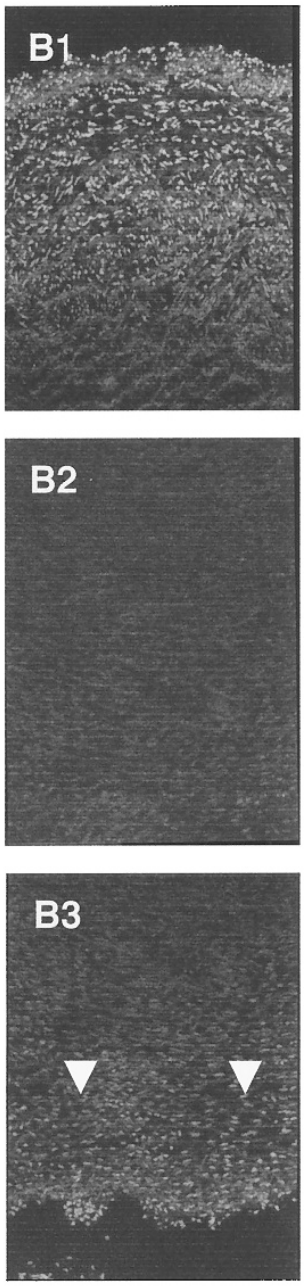

Fetus
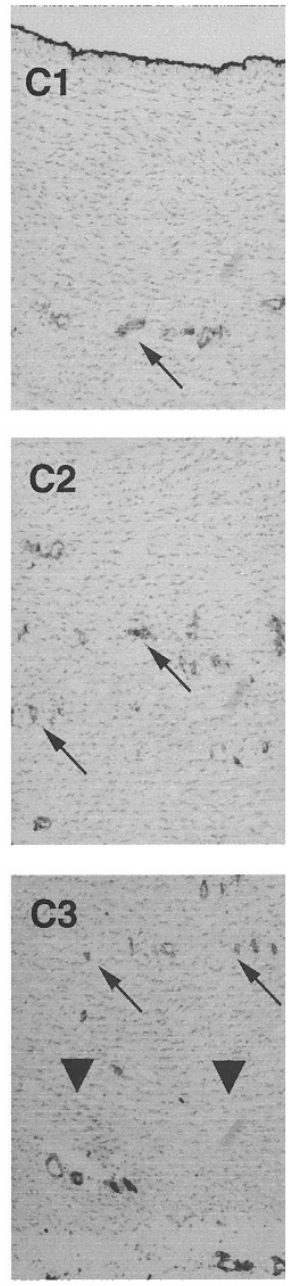

Newborn
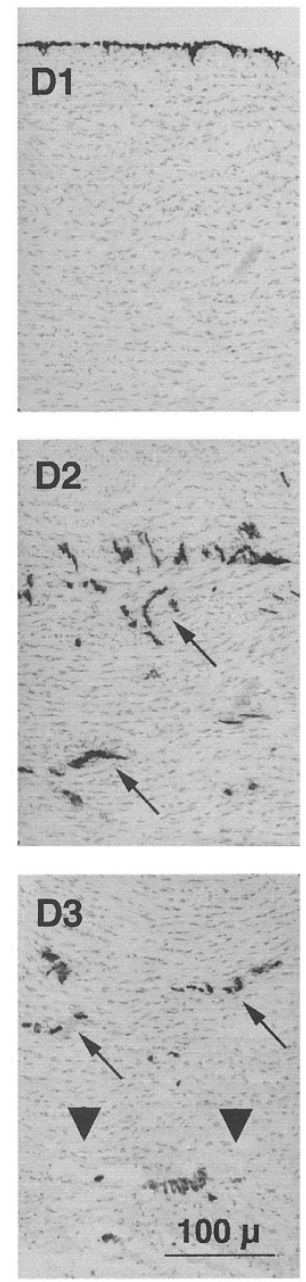

Figure 6. Hoechst-bis-benzimide nuclear staining of cells in the fetal $(A)$ and 4-h-old neonatal $(B)$ ductus. Hoechst-bis-benzimide was administered 15 min before euthanasia. Sections of the fetal $(C)$ and neonatal $(D)$ ductus were stained for eNOS (counterstain hematoxylin) to identify endothelial cells in the vasa vasorum (arrows). 1, 2, and 3 represent the luminal-, middle-, and outer-third of the ductus wall, respectively. Arrowheads indicate the beginning of the adventitia. Horizontal bar $=100 \mu \mathrm{m}$. Faint, wavy lines in $(A)$ and $(B)$ are elastic lamina in the muscle media. There was no nuclear staining in the outer muscle media of the newborn ductus $(B 2, B 3)$ despite the presence of vasa vasorum $(D 2, D 3)$ throughout the wall.

luminal flow completely. With complete luminal obstruction, oxygen and nutrients to the vessel wall would have to come exclusively from the vasa vasorum that lie in the adventitia. As a result, the vectorial oxygen diffusion distance (from the vasa vasorum to the center of the avascular DA wall) would have to increase by more than 2.5 -fold (to $0.67 \mathrm{~mm}$, the thickness of the DA wall; Fig. 7E). This would lead to profound hypoxia.
Several observations suggest that this hypothesis may indeed be correct: 1) Small animals (like mice, rats, and rabbits) lack intramural vasa vasorum just like preterm humans (3); however, in contrast with preterm humans, they completely obliterate their DA lumen within minutes of birth; after this, they undergo DA remodeling (26). 2) Similarly, when preterm newborns are made hyperoxemic or are given a combination of 


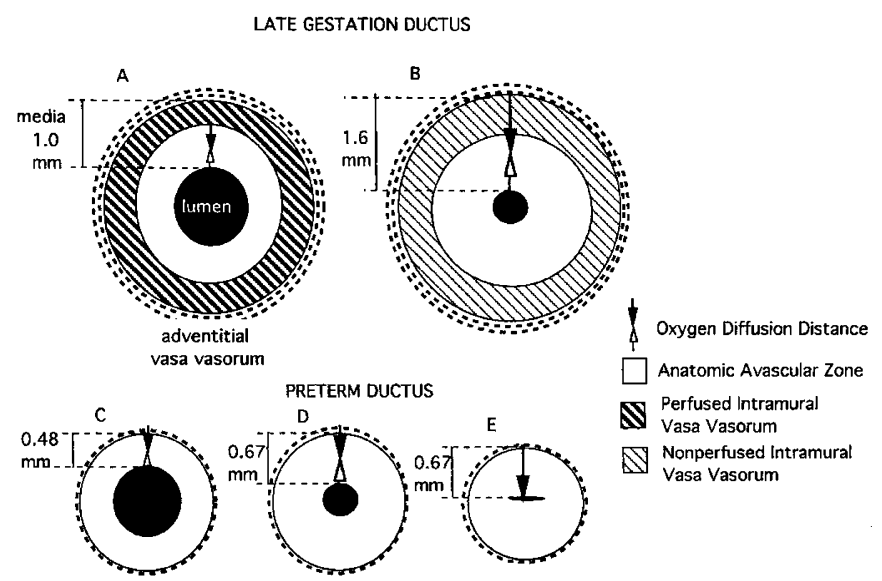

Figure 7. Different stages of ductus constriction in the late-gestation and preterm ductus. $A$, late-gestation fetal ductus; $B$, late-gestation newborn ductus; $C$, preterm fetal ductus; $D$, preterm newborn ductus; $E$, preterm newborn ductus with obliterated luminal blood flow. Anatomic avascular zone, region of the ductus wall between the ductus lumen and the leading edge of the vasa vasorum; effective avascular zone, region between the two sources of oxygen that supply the ductus wall; oxygen diffusion distance, vectorial oxygen diffusion distance from either the lumen (open arrow) or the vasa vasorum (closed arrow) to the center of the effective avascular zone.

indomethacin and L-nitro-arginine (a nitric oxide synthase inhibitor), to increase DA contractility, they obliterate their DA lumen $(14,27)$. When this occurs, the DA becomes profoundly hypoxic and undergoes the same anatomic changes as found at term $(14,27)$. These observations demonstrate that, in contrast with the full-term DA, the preterm DA requires complete obstruction of luminal flow before it can develop the same degree of hypoxia as found at term. They also underscore the critical importance of the initial constrictive phase of ductus closure in triggering the subsequent steps of ductus remodeling. Therapeutic manipulations that increase DA tone $(28-31)$ should produce both improved functional constriction as well as anatomic remodeling of the preterm DA.

Acknowledgment. The authors thank Patricia Oprysko for EF5 analysis.

\section{REFERENCES}

1. Clyman RI, Chan CY, Mauray F, Chen YQ, Cox W, Seidner SR, Lord EM, Weiss H, Wale N, Evan SM, Koch CJ 1999 Permanent anatomic closure of the ductus arteriosus in newborn baboons: the roles of postnatal constriction, hypoxia, and gestation. Pediatr Res 45:19-29

2. Narayanan M, Cooper B, Weiss H, Clyman RI 2000 Prophylactic indomethacin: factors determining permanent ductus arteriosus closure. J Pediatr 136:330-337

3. Wolinsky H, Glagov S 1967 Nature of species differences in the medial distribution of aortic vasa vasorum in mammals. Circ Res 20:409-421
4. Zemplenyi T, Crawford DW, Cole MA 1989 Adaptation to arterial wall hypoxia demonstrated in vivo with oxygen microcathodes. Atherosclerosis 76:173-179

5. Tannock IF 1972 Oxygen diffusion and the distribution of cellular radiosensitivity in tumours. Br J Radiol 45:515-524

6. Black LM 1976 Analysis of oxygen transport in the avascular region of arteries. Math Biosci 31:285-306

7. Jurrus ER, Weiss HS 1977 In vitro tissue oxygen tensions in the rabbit aortic arch. Atherosclerosis 28:223-232

8. Heistad DD, Armstrong ML, Amundsen S 1986 Blood flow through vasa vasorum in arteries and veins: effects of luminal $\mathrm{Po}_{2}$. Am J Physiol 250:H434-H442

9. Barker SG, Talbert A, Cottam S, Baskerville PA, Martin JF 1993 Arterial intimal hyperplasia after occlusion of the adventitial vasa vasorum in the pig. Arterioscler Thromb 13:70-77

10. Geiringer E 1951 Intimal vascularization and atherosclerosis. J Pathol Bact 63:201211

11. Heistad DD, Marcus ML 1979 Role of vasa vasorum in nourishment of the aorta. Blood Vessels 16:225-238

12. Clarke JA 1965 The vasa vasorum of normal human lower limb arteries. Acta Anat 61:481-487

13. Kajino H, Chen YQ, Chemtob S, Waleh N, Koch CJ, Clyman RI 2000 Tissue hypoxia inhibits prostaglandin and nitric oxide production and prevents ductus arteriosus reopening. Am J Physiol 279:R278-R286

14. Kajino H, Chen YQ, Seidner SR, Waleh N, Mauray F, Roman C, Chemtob S, Koch CJ, Clyman RI 2001 Factors that increase the contractile tone of the ductus arteriosus also regulate its anatomic remodeling. Am J Physiol 281:R291-R301

15. Koch CJ, Evans SM, Lord EM 1995 Oxygen dependence of cellular uptake of EF5 [2-(2-nitro-1H-imidazol-1-yl)- $N$-(2,2,3,3,3-pentafluoropropyl)acetamide]: analysis of drug adducts by fluorescent antibodies $v s$ bound radioactivity. Br J Cancer 72:869874

16. Clyman RI, Chen YQ, Chemtob S, Mauray F, Kohl T, Varma DR, Roman C 2001 In utero remodeling of the fetal lamb ductus arteriosus: the role of antenatal indomethacin and avascular zone thickness on vasa vasorum proliferation, neointima formation, and cell death. Circulation 103:1806-1812

17. Fineman JR, Takahashi Y, Roman C, Clyman RI 1998 Endothelin-receptor blockade does not alter closure of the ductus arteriosus. Am J Physiol 275:H1620-H1626

18. Meyers RL, Alpan G, Lin E, Clyman RI 1991 Patent ductus arteriosus, indomethacin, and intestinal distension: effects on intestinal blood flow and oxygen consumption. Pediatr Res 29:569-574

19. Austin GE, Tuvlin MB, Martino-Salzman D, Hunter RL, Justicz AG, Thompson NK, Brooks AC 1993 Determination of regional myocardial blood flow using fluorescent microspheres. Am J Cardiovasc Pathol 4:352-357

20. Clyman RI, Mauray F, Wong L, Heymann MA, Rudolph AM 1978 The developmental response of the ductus arteriosus to oxygen. Biol Neonate 34:177-181

21. Hellstrand P 1977 Oxygen consumption and lactate production of the rat portal vein in relation to its contractile activity. Acta Physiol Scand 100:91-106

22. Peterson JW, Paul RJ 1974 Aerobic glycolysis in vascular smooth muscle: relation to isometric tension. Biochim Biophys Acta 357:167-176

23. Van Citters RL, Wagner BM, Rushmer RF 1962 Architecture of small arteries during vasoconstriction. Circ Res 10:668-675

24. Clarke JA 1965 An x-ray microscopic study of the vasa vasorum of the human ductus arteriosus. J Anat 99:527-537

25. Buerk DG, Goldstick TK, Ernest JT, Dobrin PB 1981 Oxygen tension profiles and oxygen consumption inhomogeneities in the arterial wall: implications for atherosclerosis. Adv Physiol Sci 25:23-24

26. Hornblad PY 1967 Studies on closure of the ductus arteriosus. 3. Species differences in closure rate and morphology. Cardiology 51:262-282

27. Seidner SR, Chen Y-Q, Oprysko PR, Mauray F, Tse MM, Lin E, Koch C, Clyman RI 2001 Combined prostaglandin and nitric oxide inhibition produces anatomic remodeling and closure of the ductus arteriosus in the premature newborn baboon. Pediatr Res 50:365-373

28. Tristani-Firouzi M, Reeve HL, Tolarova S, Weir EK, Archer SL 1996 Oxygeninduced constriction of rabbit ductus arteriosus occurs via inhibition of a 4-aminopyridine-, voltage-sensitive potassium channel. J Clin Invest 98:1959-1965

29. Michelakis E, Rebeyka I, Bateson J, Olley P, Puttagunta L, Archer S 2000 Voltagegated potassium channels in human ductus arteriosus. Lancet 356:134-137

30. Coceani F, Kelsey L, Seidlitz E 1992 Evidence for an effector role of endothelin in closure of the ductus arteriosus at birth. Can J Physiol Pharmacol 70:1061-1064

31. Wu GR, Jing S, Momma K, Nakanishi T 2001 The effect of vitamin A on contraction of the ductus arteriosus in fetal rat. Pediatr Res 49:747-754 